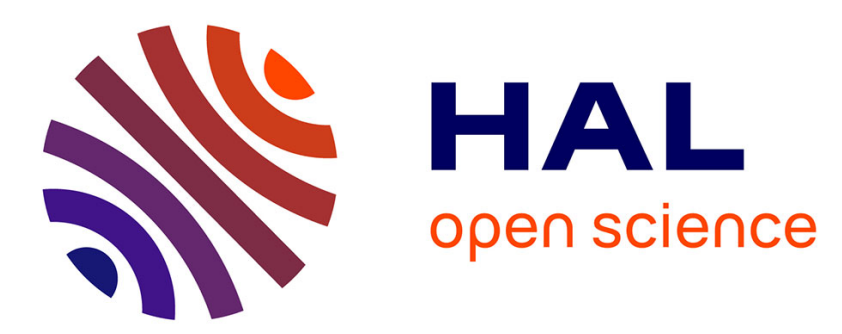

\title{
A new contactless conveyor system for handling clean and delicate products using induced air flows.
}

\author{
Anne Delettre, Guillaume J. Laurent, Nadine Le Fort-Piat
}

\section{To cite this version:}

Anne Delettre, Guillaume J. Laurent, Nadine Le Fort-Piat. A new contactless conveyor system for handling clean and delicate products using induced air flows.. IEEE/RSJ International COnference on Intelligent Robots and Systems, IROS'10., Oct 2010, Taipei, Taiwan. pp.2351-2356. hal-00544593

\section{HAL Id: hal-00544593 \\ https://hal.science/hal-00544593}

Submitted on 8 Dec 2010

HAL is a multi-disciplinary open access archive for the deposit and dissemination of scientific research documents, whether they are published or not. The documents may come from teaching and research institutions in France or abroad, or from public or private research centers.
L'archive ouverte pluridisciplinaire HAL, est destinée au dépôt et à la diffusion de documents scientifiques de niveau recherche, publiés ou non, émanant des établissements d'enseignement et de recherche français ou étrangers, des laboratoires publics ou privés. 


\title{
A New Contactless Conveyor System for Handling Clean and Delicate Products Using Induced Air Flows
}

\author{
Anne Delettre, Guillaume J. Laurent and Nadine Le Fort-Piat
}

\begin{abstract}
In this paper, a new contactless conveyor system based on an original aerodynamic traction principle is described and experimented. This device is able to convey without any contact flat objects like silicon wafer, glass sheets or foodstufff thanks to an air cushion and induced air flows. A model of the system is established and the identification of the parameters is carried out. A closed-loop control is proposed for one dimension position control and position tracking. The PID-controller gives good performances for different reference signals. Its robustness to object change and perturbation rejection are also tested.
\end{abstract}

\section{INTRODUCTION}

Many industries require contactless transport and positioning of delicate or clean objects such as silicon wafers, glass sheets, solar cell or flat foodstuffs. The handling of delicate, freshly painted, hot, sensitive or micron-sized structured components is feasible because mechanical contact is avoided. Contamination from and of the end-effectors can be totally avoided. This can be important in food handling or in semiconductor production processes. Furthermore, dry friction forces are canceled, which enables accurate positioning or high velocity motions.

In order to avoid contact between feeding devices and work pieces, many handling approaches have been proposed. These methods typically employ magnetic, electrostatic, near-field and aerodynamic levitation [1]. Both magnetic and electric levitation are restricted to conductive materials and the lifting force depends on material properties. Pneumatic levitation approaches use air flow to apply a force to a work piece. Because air flow is magnetic free and generates little stress, pneumatic approaches can be applied to any material: insulator or conductor, magnetic or non-magnetic, rigid or non-rigid.

Researchers have experimented a variety of air-jet techniques to design contactless manipulators. Aerodynamic levitation uses a flow of gas to apply a lift force. Two different approaches can be considered: air cushion or Bernoulli levitation. In Bernoulli levitation, the sample is held below the end-effector of the manipulator which consists in a cupshaped air nozzle [2]. Bernoulli levitation has been used in practical applications to "pick-and-place" wafers [3] and flat soft foodstuffs [4].

In air cushion levitation, the sample is held on a plate which is drilled by many small holes. Pressurized air flows

This work was supported by the Smart Surface NRA (French National Research Agency) project (ANR_06_ROBO_0009)

A. Delettre, G. J. Laurent,and N. Le Fort-Piat are with the Automatic Control and Micro-Mechatronic Systems Department, FEMTO-ST Institute, UFC-ENSMM-UTBM-CNRS, Université de Franche-Comté, Besançon, France, $\{$ Firstname. Lastname $\}$ dens $2 m$. fr upward through these holes and create an air cushion that counterbalances the weight of the component. This is the principle of popular air-hockey tables. To propel the object levitating on the table, two principles have been proposed: suction and inclined air jet.

Luntz and Moon [5], [6] use an air-hockey table in addition to few flow sinks (suction points) above the table. The sinks create a stable flow pattern towards them. This device is a sensorless positionning surface able to move any rectangular objects to a predictable orientation and position. Ku et al. [7] developed the same idea but they used closed-loop control to move the object from one sink to another. The device is an $4 \mathrm{~mm} \times 4 \mathrm{~mm}$ array of 100 capillary glass tubes. Each tube is equipped with a pressure sensor and a two-position valve to provide positive or negative pressures. The typical velocity of the object is $8 \mathrm{~mm} . \mathrm{s}^{-1}$.

Many devices use arrays of inclined air-jets to produce a traction force in addition to the air cushion. The geometry of most of devices is designed to get stable transport system without closed-loop control, for example we can mentioned wafer and glass transportation systems [8], [9], [10]. In contrast, the Xerox PARK paper handling system [11], [12] uses 1,152 separately controllable and directed air-jets in a 12 in. $\times 12$ in. array to levitate paper sheets. The flow for each jet is controlled by an independent MEMS-like valve. 32,000 optical sensors (photodiodes) are integrated between actuators to sense and control the paper position. The levitation-transport system uses two arrays of 578 valves arranged in opposition to one another across a small gap in which the paper is situated. The system has demonstrated closed-loop positioning accuracies in the order of $0.05 \mathrm{~mm}$ and trajectory tracking with typical velocity about $30 \mathrm{~mm} . \mathrm{s}^{-1}$. Rij et al. [13] proposed a wafer transport concept based on viscous traction principle. The device is designed to produce horizontal air flow under the wafer. The principle is then similar to the paper handling system. On a near microscopic scale, some active surface have been developed using MEMS actuator arrays. The surface of Fukuta [14] is able to produce inclined air-jets thanks to integrated electrostatic valves. In their experiments a flat plastic piece was successfully move with a velocity in the order of $4.5 \mathrm{~mm} . \mathrm{s}^{-1}$.

This paper introduces a device able to move an object on an air-hockey table thanks to a new traction principle. The system uses neither inclined air jet nor suction nozzle. The object is moved indirectly by an air flow which is induced by some strong vertical air jets. These strong jets are coming from some specific orifices of the air-hockey 




(a) Global view

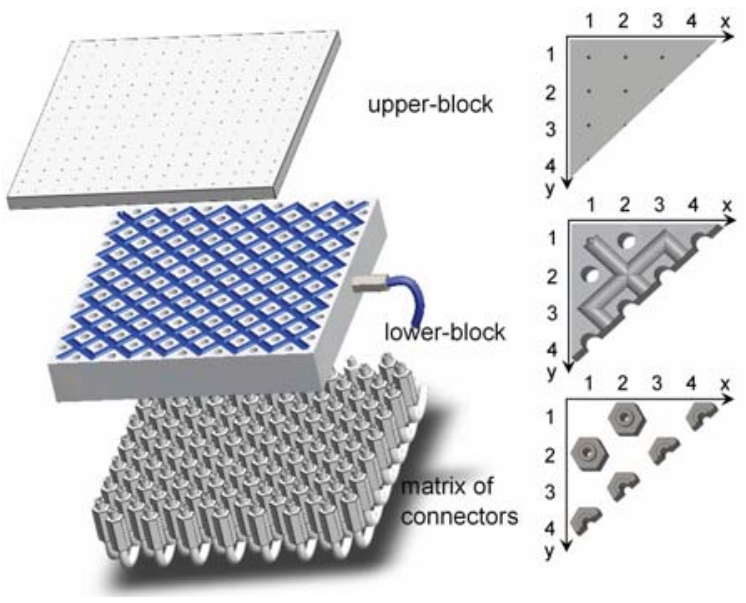

(b) Exploded view

Fig. 1. The induced air flow surface.

table. This paper is organized as follow: the first part presents a qualitative explanation of the operating principles and a description of the experimental device called induced air flow surface. The second part presents the choice for the control signal nature. The third part describes the identification of the system and the fourth one the closed-loop control of the device. The last part present the first experimental results, their analysis and some discussions.

\section{INDUCED AIR FLOW SURFACE}

The induced air flow surface is a $120 \times 120 \mathrm{~mm}^{2}$ square surface upon which an object is moving in aerodynamic levitation. The device consists of two parts detailed in the exploded view of the figure 1 :

- The upper-block is drilled of $15 \times 15$ nozzles; each nozzle is $0.4 \mathrm{~mm}$ in diameter;

- The lower-block is drilled of 112 holes in staggered columns; These holes connect one hole out of two of the upper-block to independent air inlets; between holes a network of diagonal channels connects the other holes of the upper-block to a common air inlet located on the side of the lower-block.

The object is maintained in constant levitation thanks to an air cushion created by the airflow that comes through

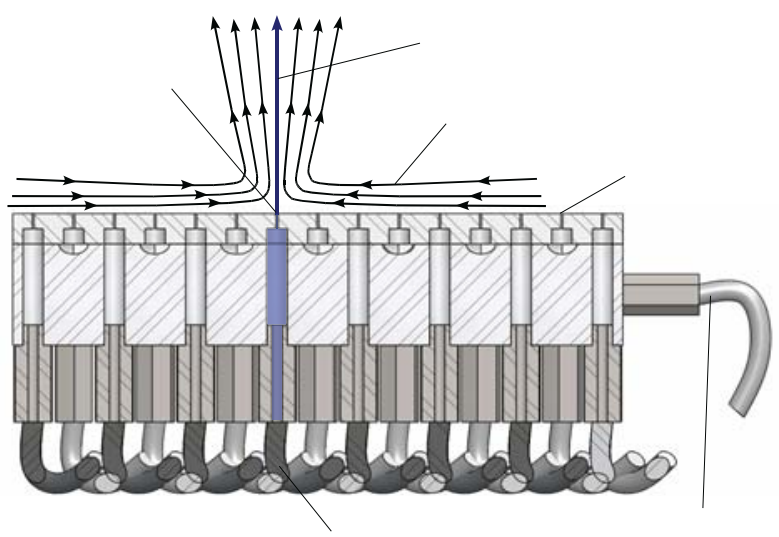

Fig. 2. Cross view of the induced air flow surface with one opened valve

the lateral common air inlet. The airflow spreads over the network of diagonal channels and then through one hole out of two of the upper-block.

An object can be moved by generating strong vertical air-jets through the others holes of the surface. Each nozzle is driven by an independent solenoid valve ( $3 / 2$ normally closed valve). When a valve is open, air-flow comes through both blocks and generates a vertical air-jet on the front side of the upper-block. The air-jet creates an induced air flow in the surrounding fluid that pull the object toward the nozzle (cf. figure 2). This traction phenomena is a counter-intuitive physics demonstration of fluid mechanics such as the popular Bernoulli levitation [2]. It would be very interesting in future works to describe it in a more formal and quantitative way.

The experimental setup for the distributed-air-jet manipulator is composed of pressurized air supply, two pressure regulators, the set of solenoid valves and its control system, and a computer for vision processing. Figures 3 and 4 describes the complete hardware configuration.

The induced air flow surface is put on a mechanical platform to adjust its equilibrium position. The air-flow source is provided by compressed air via two pressure control systems. One system controls the levitation and the other supplies air pressure for the valves. Default settings for operating pressures are $10 \mathrm{kPa}$ for levitation and $500 \mathrm{kPa}$ for traction.

Each valve is independently actuated by an electric signal. The electrical voltage applied to the valves is $24 \mathrm{~V} \mathrm{DC}$. Control signals are sent by computer via multi-channel digital output board (NI USB-6509) and 5V/24V amplifier circuit.

A camera is used to grab video frames of the surface of the manipulator. The image processing is realized in central process unit (CPU) of a computer at the rate of 30 frames per second (the software is OpenCV). 


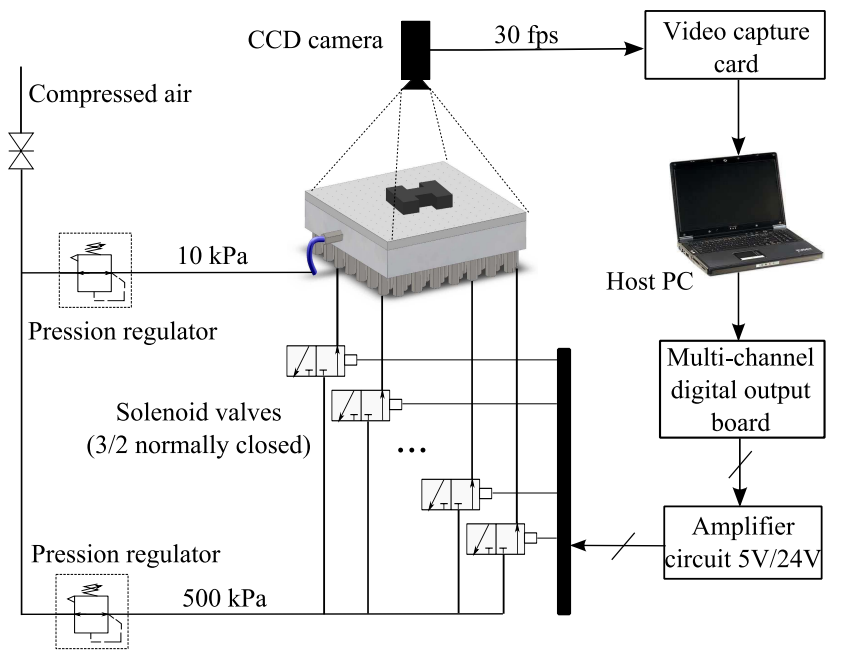

Fig. 3. Complete hardware configuration.

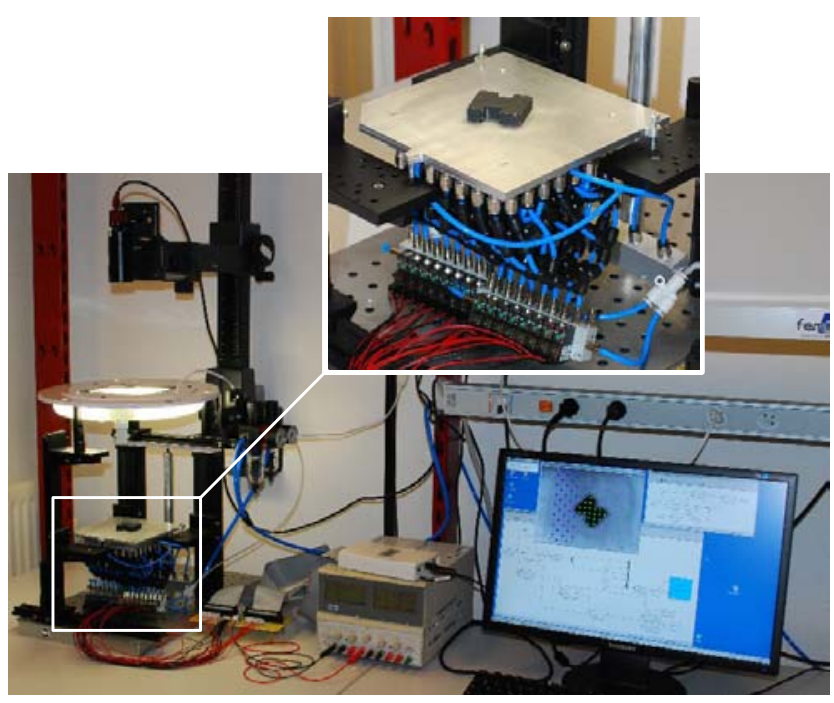

Fig. 4. Overview of the experimental setup.

\section{THE CONTROL SIGNAL}

The long term objective with this system is to control three degrees of freedom of an object (two directions and one angle). In this paper, we focus on 1D-control for doing first experiments and establishing a model of the system. Furthermore, we use the same object for all experiments: an aluminium cylindrical object. This object is $30 \mathrm{~mm}$ in diameter and $15 \mathrm{~mm}$ high, and its mass is $29 \mathrm{~g}$. As it has a rotation axis, its orientation has no consequences on its position control.

For 1D-moving, all the traction inlets of a same column are connected to the same valve. So every one valve is connected to every one column of holes of the lower block. Any combination of valves can be realized so a complete control signal is a vector of length 15 with values 0 (for a closed valve) or 1 (for an open valve). As some combinations produce almost the same effect on the object, we first selected the ones shown on figure 5 and following these

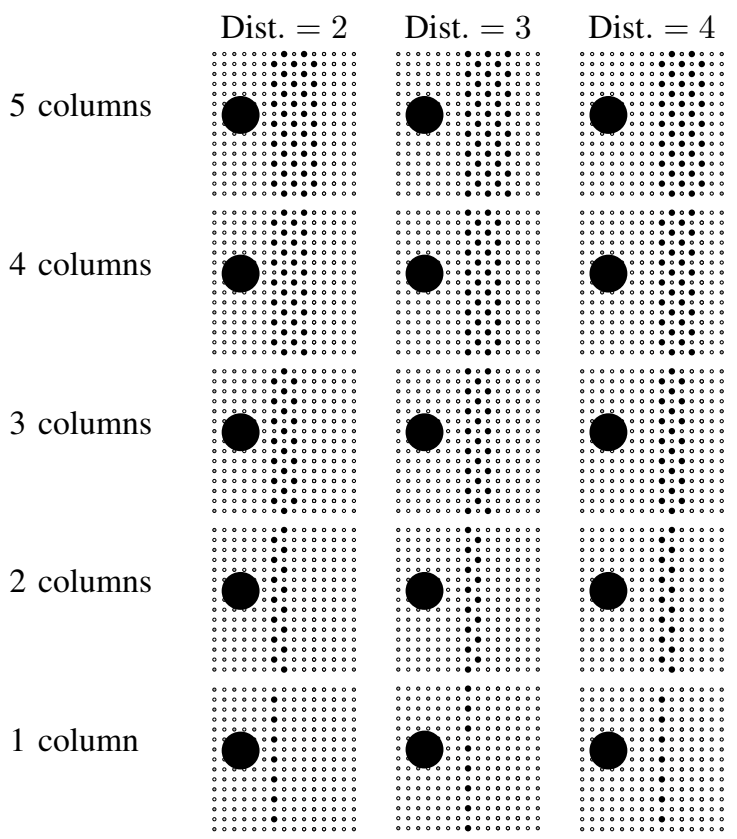

Fig. 5. Different combinations depending on the number of active columns and their distance to the object. A small filled black circle represents a traction nozzle connected to an open valve and the big black circle the object to move.

properties:

- The active columns must be situated in the same side of the object;

- The active columns must be consecutives;

- The columns located under the object and in the first column closed to it cannot be opened. Indeed, an air jet flow that would be induced by holes situated next to the object would lift it, what would lead to a complex behaviour of the moving object.

When one or more valves are open, the object moves thanks to the air flow induced by the vertical air jets, in its direction (see figure 6).

The measured object velocity at the exit of the active surface for each combination shown on figure 5 is reported in figure 7 . The maximum range of velocity values is achieved for a distance 2 , that is to say the first active hole column close to the object is the second one. The control signal is defined as the number of columns to activate (the number of valves to open); it is set to this value of 2 . The signal is positive if the active columns are at the east of the object and negative if the active columns are at the west of the object (see figure 8).

\section{IDENTIFICATION}

\section{A. Model of the air flow surface}

By observing the step response (figure 6) we can conclude that the system is a second order one with an integrator. The model of the whole system composed of the smart surface and the object to move, is given by the following transfer 


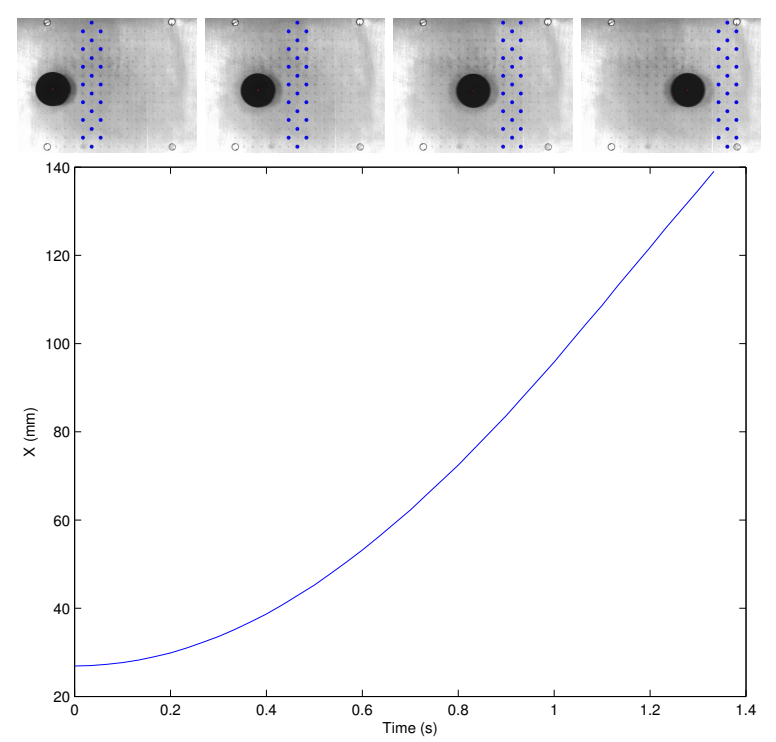

Fig. 6. Image sequence and position versus time during an open loop control experiment with three active columns and a distance value of 2 . On the images, the big black circle is the object and the drawn dark small circles represent holes connected to open valves.

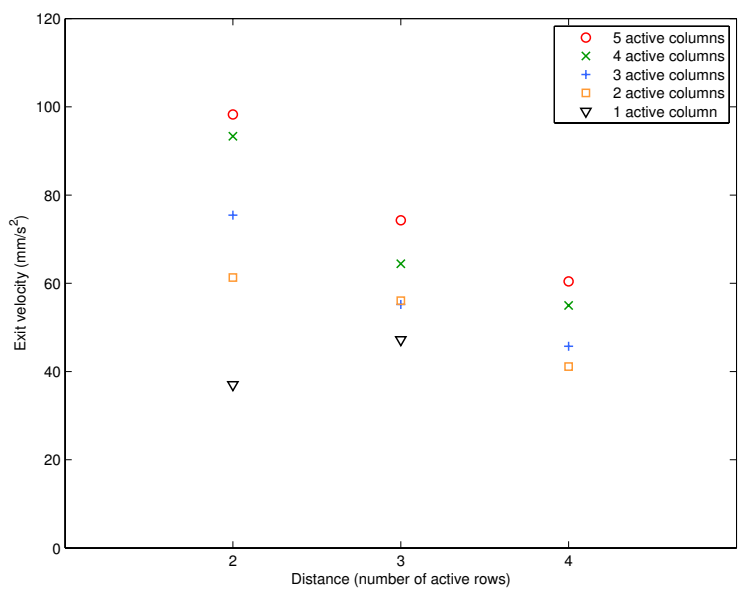

Fig. 7. Exit velocities of the object according to the number of active columns and their distance to it.

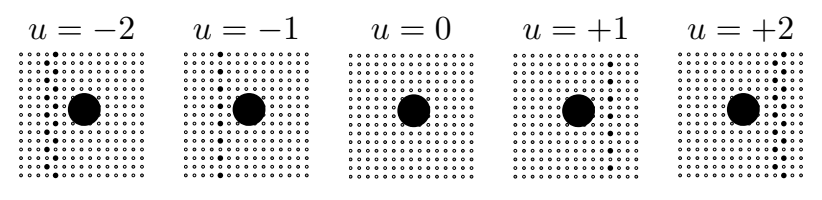

Fig. 8. The control signal $u$ is an integer which represents the number of hole columns to open; it can be either positive or negative. A grey circle corresponds to a levitation nozzle, a small black one to a traction nozzle connected to an open valve and a white one to a closed valve. The big black circle represents the object to move.

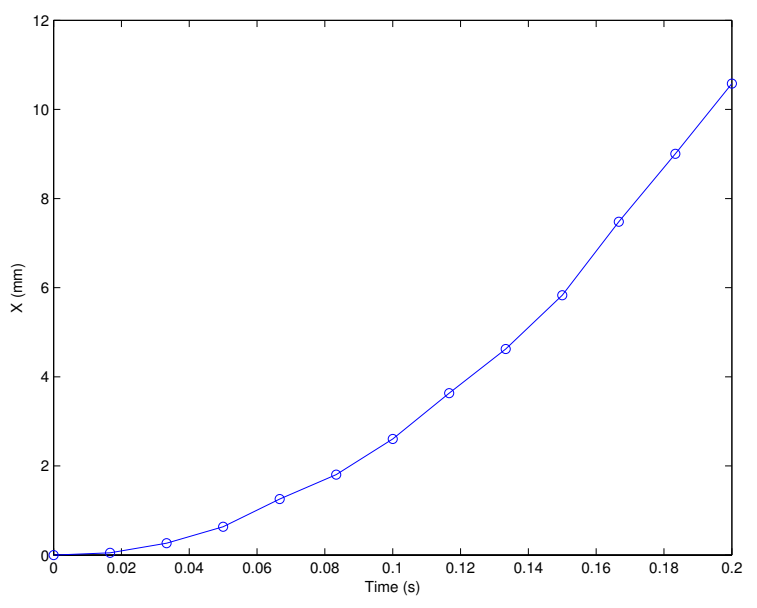

Fig. 9. Position of an object of negligible mass as a function of time, with one valve opened at time 0 .

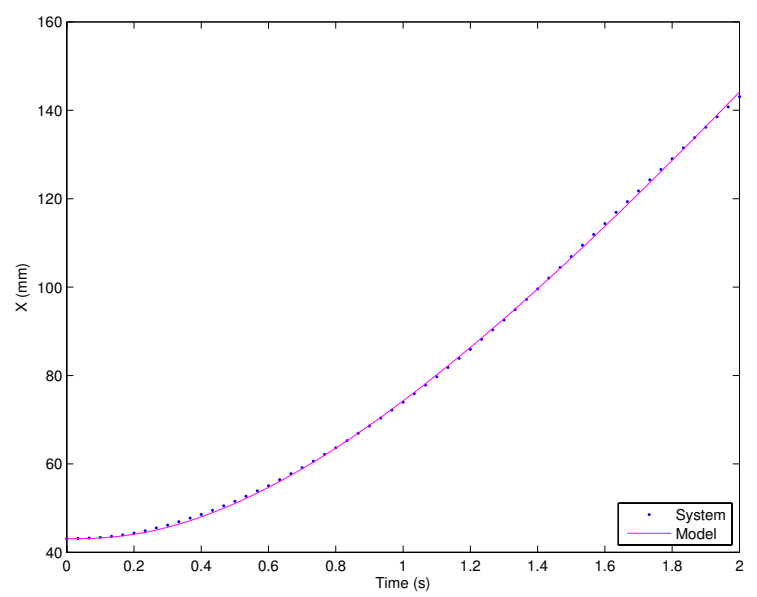

Fig. 10. Comparison between the model and the experimental data (average on 5 experiments). The reference signal is a step whose amplitude is 2 .

fonction:

$$
G(p)=\frac{X(p)}{U(p)}=\frac{k}{p\left(1+\tau_{1} p\right)\left(1+\tau_{2} p\right)}
$$

where $X$ is the Laplace variable corresponding to the output of the system which is the position of the object in $\mathrm{mm}$ and $U \in \mathbb{R}$ the Laplace variable corresponding to the control signal. The parameter $\tau_{1}=0.085 \mathrm{~s}$ corresponds to the establishment of the induced air flow, including the dynamic of the valves. It can be identified on figure 9 which represents the plot of the trajectory of an object whose mass is negligible.

The other parameters $k$ and $\tau_{2}$ depend on the object to move and have to be identify for each object. For example, their values for the alumium cylinder-shaped object are: $k=$ 41.75 and $\tau_{2}=0.773 \mathrm{~s}$. They have been averaged on five experiments.

The comparison between the real system and the model is shown on figure 10: it represents the position of the object in response to a step reference signal whose amplitude is 2 . 


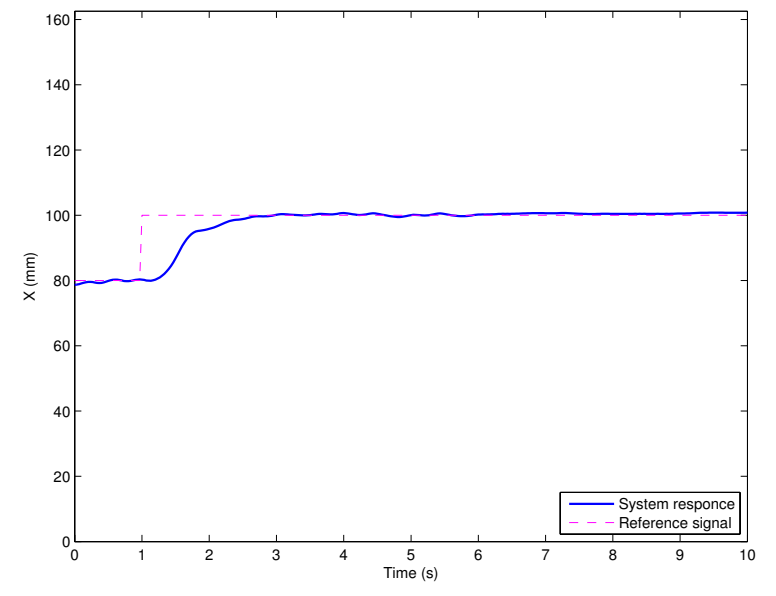

Fig. 11. X-trajectory of the object for a step reference signal in closed loop control.

\section{B. Performances}

The model of the surface can be used to do simulations for a bigger active surface and estimate its expected performances. With a one meter long active surface, the maximum velocity the object could reach is $83.50 \mathrm{~mm} / \mathrm{s}$ with 2 valves open and $166.98 \mathrm{~mm} / \mathrm{s}$ with 4 . The settling time of the object velocity is $2.47 \mathrm{~s}$ for both control signals.

\section{Closed-Loop CONTROL}

This part presents experimental results with a PIDcontroller. Performances has been evaluated through a series of experiments, which can be further appreciated in the video clip accompanying this paper ${ }^{1}$.

\section{A. PID controller}

The aim of the closed-loop control is to control the position of a given object. The controller is Proportionnal (P) Integral (I) Differential (D). We use the parallel form of the PID-controller in which all three $P, D$ and $I$ actions are on the error $\epsilon$ between the system output and the reference. This numerical controller is given by:

$$
U(z)=\left(k_{p}+k_{i} T_{s} \frac{z}{z-1}+\frac{k_{d}}{T_{s}} \frac{z-1}{z}\right) \epsilon(z)
$$

where $z$ is the Z-transform variable, $k_{p}, k_{i}$ and $k_{d}$ the controller parameters and $T_{s}$ the sampling time. The control signal $U$ calculated by the controller is the number of valves columns to activate. It is rounded before being sent to the system in order to be an integer. As explained in section III, it can be either positive or negative.

The PID-controller is tuned manually with the same object as previously. The $k_{p}, k_{i}$ and $k_{d}$ coefficients are defined by trial-and-error in order to find a good trade off between rise time, overshoot, and stability. Their value are respectively 2 , 0.15 and 1.

\footnotetext{
${ }^{1}$ Also available at http://www.femto-st.fr/ guillaume.laurent/
}

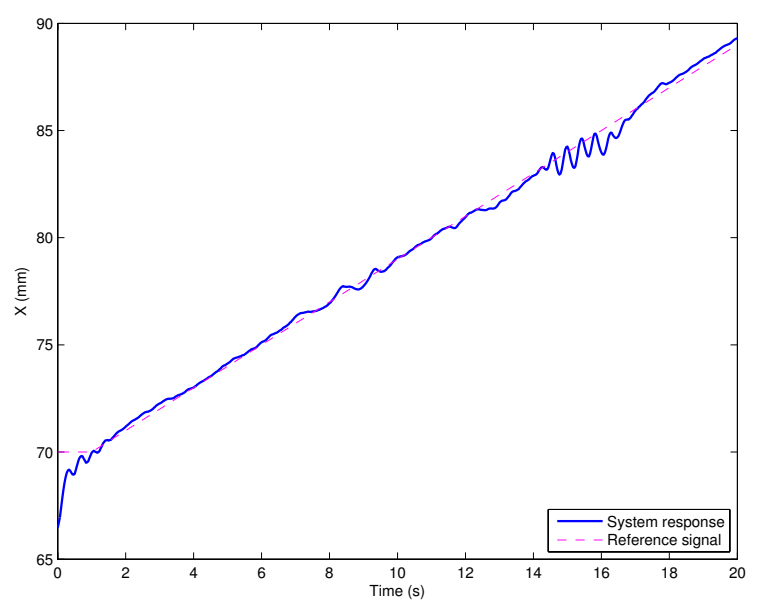

Fig. 12. X-trajectory of the object in a position tracking with a closed loop control, for a ramp reference signals.

\begin{tabular}{|c|c|c|c|}
\hline Object & $\begin{array}{c}\text { Diameter } \\
(\mathrm{mm})\end{array}$ & $\begin{array}{c}\text { Width } \\
(\mathrm{mm})\end{array}$ & $\begin{array}{c}\text { Mass } \\
(\mathrm{g})\end{array}$ \\
\hline Thick aluminium cylinder & 30.00 & 15.00 & 29.00 \\
\hline Thin aluminium cylinder & 29.95 & 5.03 & 9.80 \\
\hline Thin plastic cylinder & 30.08 & 5.15 & 3.29 \\
\hline Thick plastic cylinder & 30.01 & 15.02 & 8.57 \\
\hline
\end{tabular}

TABLE I

CHARACTERISTICS OF THE OBJECTS USED IN THE CONTROL.

\section{B. Position control}

The first experiment consists in positionning the object at the center of the active surface along the $\mathrm{x}$-axis. The position of the object along the $\mathrm{x}$-axis as a function of time for one experiment is shown on figure 11 .

The performances of the controlled system are good: the overshoot is $4.11 \%$, the rise time $1 \mathrm{~s}$ and the settling time $1.60 \mathrm{~s}$.

\section{Position tracking}

Different trajectories are tested for trajectory tracking with the same PID tuning as previously. The system responses are shown in figures 12 and 13. The average tracking error (on five experiments) is $0.242 \mathrm{~mm}$ for the ramp reference signal.

\section{Robustness}

In order to test the robustness of the controller, experiments changing one physical or geometrical property of the object are carried out. The characteristics of these objects are summed up in table I.

For a ramp reference signal, the mean tracking error is $0.198 \mathrm{~mm}$ for the thin aluminium cylinder, $2.49 \mathrm{~mm}$ for the thin plastic cylinder and $2.01 \mathrm{~mm}$ for the thick one. The trajectory of the plastic objects is oscillating that shows the limit of the PID-controller robustness. But the system remains stable.

\section{E. Perturbation rejection}

The disturbance is an horizontal air jet in the X-direction during $0.5 \mathrm{~s}$. The trajectory of the object is shown on 

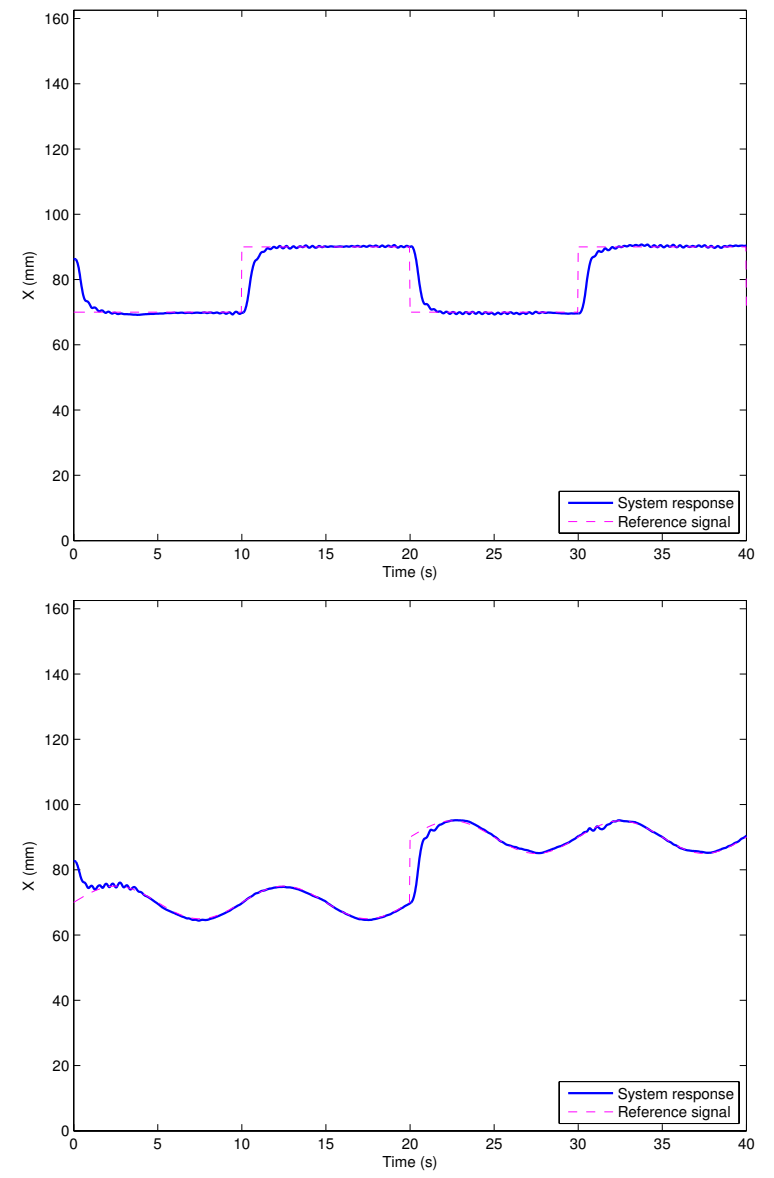

Fig. 13. X-trajectory of the object in a position tracking with a closed loop control, for different reference signals.

figure 14. The performances of the controller are not very good: oscillations appear, but the perturbation is finally rejected.

\section{CONCLUSION}

In this paper, we have described and experimented a new contactless conveyor based on an original aerodynamic traction principle. A model of the system has been established and the parameters have been identified. A PID-controller has been tuned for 1D-position control and tracking. It gives good performances for the cylindrical object but is not very robust to changes of geometrical or physical properties of the object. Indeed, such changes affect the parameter values of the model so further works may consist in tuning a robust adaptive controller. Moreover, other futur works will consist in controlling three degrees of freedom of the object (two translations and one rotation). The manipulation will be distributed thanks to independent valve control.

\section{ACKNOWLEDGMENT}

The authors gratefully acknowledge Joël Agnus and David Guibert from the FEMTO-ST Institute for their technical assistance.

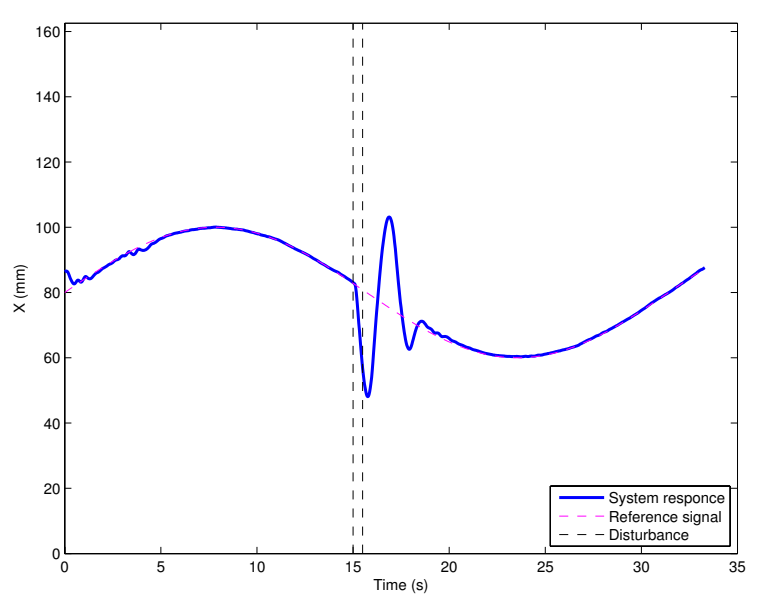

Fig. 14. X-trajectory of the object for a step reference signal in closed-loop control and including a disturbance (an horizontal air jet).

\section{REFERENCES}

[1] Vincent Vandaele, Pierre Lambert, and Alain Delchambre. Noncontact handling in microassembly: Acoustical levitation. Precision Engineering, 29:491-505, 2005.

[2] Chris Waltham, Sarah Bendall, and Andrzej Kotlicki. Bernoulli levitation. American Journal of Physics, 71(2):176-179, 2003.

[3] Xin Li, Kenji Kawashima, and Toshiharu Kagawa. Analysis of vortex levitation. Experimental Thermal and Fluid Science, 32:1448-1454, 2008.

[4] S. Davis, J.O. Gray, and Darwin G. Caldwell. An end effector based on the bernoulli principle for handling sliced fruit and vegetables. Robotics and Computer-Integrated Manufacturing, 24:249-257, 2008.

[5] Jonathan Luntz and Hyungpil Moon. Distributed manipulation with passive air flow. In Proc. of the IEEE Int. Conf. on Intelligent Robots and Systems, pages 195-201, 2001.

[6] Hyungpil Moon and Jonathan Luntz. Distributed manipulation of flat objects with two airflow sinks. IEEE Transactions on robotics, 22(6):1189-1201, 2006.

[7] Peng-Jui Ku, K. Tobias Winther, and Harry E. Stephanou. Distributed control system for an active surface device. In Proc. of the IEEE Int. Conf. on Intelligent Robots and Systems, pages 3417-3422, 2001.

[8] M. Hoetzle, T. Dunifon, and L. Rozevink. Glass transportation system. U.S. Patent 6,505,483, 2003.

[9] J. A. Paivanas and J. K. Hanssan. Wafer air film transportation system. U.S. Patent 4,081,201, 1978

[10] J. P. Babinski, B. I. Bertelsen, K. H. Raacke, V. H. Sirgo, and C. J. Townsend. Transport system for semiconductor wafer multiprocessing station system. U. S. Patent 3,976,330, 1976.

[11] Andrew Berlin, David Biegelsen, Patrick Cheung, Markus Fromherz, David Goldberg, Warren Jackson, Bryan Preas, James Reich, and LarsErik Swartz. Motion control of planar objects using large-area arrays of mems-like distributed manipulators. Micromechatronics, 2000.

[12] David K. Biegelsen, Andrew Berlin, Patrick Cheung, Markus P.J. Fromherz, David Goldberg, Warren B. Jackson, Bryan Preas, James Reich, and Lars-Erik Swartz. Air-jet paper mover: An example of meso-scale mems. In SPIE Int. Symposium on Micromachining and Microfabrication, 2000.

[13] J. van Rij, J. Wesselingh, R. A. J. van Ostayen, J.W. Spronck, R.H. Munnig Schmidt, and J. van Eijk. Planar wafer transport and positioning on an air film using a viscous traction principle. Tribology International, 42:1542-1549, 2009.

[14] Y. Fukuta, Y.-A. Chapuis, Y. Mita, and H. Fujita. Design, fabrication and control of mems-based actuator arrays for air-flow distributed micromanipulation. IEEE/ASME Journal of Microelectromechanical Systems, 15(4):912-926, 2006. 